\title{
Cobalamin and Folate Status among Breastfed Infants in Bhaktapur, Nepal
}

\author{
Ram K. Chandyo 1,2,*, Manjeswori Ulak ${ }^{3}$, Ingrid Kvestad ${ }^{4}$, Mari Hysing ${ }^{4}$, Merina Shrestha ${ }^{3}$, \\ Suman Ranjitkar ${ }^{3}$, Arve Ulvik ${ }^{5}$, Per Magne Ueland ${ }^{5}$, Laxman Shrestha ${ }^{3}$ \\ and Tor A. Strand 1,6,7 (D) \\ 1 Centre for Intervention Science in Maternal and Child Health, Centre for International Health, \\ University of Bergen, P.O. Box 7800, 5020 Bergen, Norway; tor.strand@uib.no \\ 2 Department of Community Medicine, Kathmandu Medical College, P.O. Box 21266, Sinamangal, \\ Kathmandu, Nepal \\ 3 Department of Child Health, Institute of Medicine, P.O. Box 1524, Kathmandu, Nepal; \\ manjeswori@gmail.com (M.U.); drmerinashrestha@gmail.com (M.S.); sumanra7@gmail.com (S.R.); \\ laxmanshree12@gmail.com (L.S.) \\ 4 Regional Center for Child and Youth Mental Health and Child Welfare, West, Uni Research Health, \\ P.O. Box 7810, 5020 Bergen, Norway; ingrid.Kvestad@uni.no (I.K.); mari.hysing@uni.no (M.H.) \\ 5 Department of Clinical Science, University of Bergen, P.O. Box 7800, 5020 Bergen, Norway; \\ arve.ulvik@uib.no (A.U.); per.ueland@ikb.uib.no (P.M.U.) \\ 6 Innlandet Hospital Trust, P.O. Box 990, 2629 Lillehammer, Norway \\ 7 Lillehammer University College, P.O. Box 952, 2604 Lillehammer, Norway \\ * Correspondence: ram.chandyo@uib.no; Tel.: +977-01-6618007
}

Received: 21 February 2018; Accepted: 16 May 2018; Published: 18 May 2018

\begin{abstract}
Cobalamin and folate are crucial micronutrients during infancy and they are required for growth and cognitive development. Due to the monotonous and predominantly vegetarian-based complementary feeding and poor maternal micronutrient status, infants from low- and middle-income countries are susceptible to cobalamin deficiency. However, data on plasma cobalamin and folate and the functional markers methylmalonic acid and total homocysteine from breastfed infants in Nepal are still needed. We collected plasma samples from 316 6-11-month-old breastfed infants with a length-for-age of less than minus one $z$-score and analyzed blood for plasma folate, cobalamin, methylmalonic acid and total homocysteine concentrations. Cobalamin deficiency (plasma cobalamin $<148 \mathrm{pmol} / \mathrm{L}$ ) was found among $11 \%$, whereas $24 \%$ of the infants had plasma cobalamin concentrations between 148-221 pmol/L. Elevated total homocysteine $(>10 \mu \mathrm{mol} / \mathrm{L})$ and methylmalonic acid $(>0.28 \mu \mathrm{mol} / \mathrm{L})$ indicating functional cobalamin deficiency were found among $53 \%$ and $75 \%$ of the infants, respectively. Based on a combined indicator of cobalamin status, $58 \%$ were found to have low cobalamin status. However, folate deficiency $(<10 \mathrm{nmol} / \mathrm{L})$ was not found as the lowest value of plasma folate was $20.7 \mathrm{nmol} / \mathrm{L}$. It is important to examine the extent to which poor cobalamin status during infancy has immediate or long-term consequences.
\end{abstract}

Keywords: cobalamin; folate; infants; combined $\mathrm{B}_{12}$; methylmalonic acid; homocysteine and Nepal

\section{Introduction}

Both cobalamin (vitamin $\mathrm{B}_{12}$ ) and folate are important for proper growth and cognitive development as they are required for normal cell division, maturation of red blood cells and myelination of the central nervous system [1-3]. Due to the monotonous vegetarian-based complementary feeding practices and/or maternal malnutrition in low- and middle-income countries, cobalamin deficiency is common [4-8]. Deficiencies of cobalamin and folate during the early stages of 
life may not only lead to immediate negative consequences for growth and increased morbidity, but have also been associated with later neurodevelopment [9-13]. However, there are no specific clinical manifestations that can be used to diagnose cobalamin and folate deficiencies during the early stages, particularly among infants. The available biochemical indicators of cobalamin and folate status are of different sensitivity and specificity $[14,15]$. Moreover, only $6-20 \%$ of plasma cobalamin, which is widely used to define cobalamin deficiency [16], exists in its active form, bound to transcobalamin [17]. This underlines the importance of the functional markers methylmalonic acid (MMA) and total homocysteine (tHcy), and a recently proposed combined indicator of cobalamin status $\left(3 \mathrm{cB}_{12}\right)$ [18].

For infants of 7-12 months, $0.7 \mu \mathrm{g}$ of cobalamin per day is set as the requirement, but achieving this amount from vegetarian-based complementary feeding is unlikely $[19,20]$. Breast milk is an excellent source for many vitamins and minerals, but not for cobalamin, and hence many exclusively breastfed infants are at risk for cobalamin deficiency [21]. Infant cobalamin status also depends on maternal status during pregnancy [22-25]. Infants born to mothers with low cobalamin status are more likely to be cobalamin-deficient compared to infants of mothers with normal status, probably due to poor trans-placental transfer and low storage of cobalamin [14,26].

Poor cobalamin status in combination with high serum folate levels may exacerbate neurological damage and could also worsen poor cognitive function in adults [27]. In the one-carbon metabolic pathway, poor function of the cobalamin-dependent enzyme methionine synthase may lead to trapping of folate as 5-methyl tetrahydrofolate [28]. Deficiencies of both cobalamin or folate also may cause megaloblastic anemia leading failure to thrive, and developmental delay [29].

In Nepal, stunting is a common form of malnutrition among children affecting approximately one third of children under the age of 5 . Of women, $17 \%$ are undernourished $\left(\mathrm{BMI}<18.5 \mathrm{~kg} / \mathrm{m}^{2}\right)$ (NDHS 2016). The prevalence of anemia is also high affecting approximately 53\% [30]. However, data on status of micronutrients including cobalamin and folate from breastfed infants from Nepal are still lacking. Because of rapid growth and development, infants are particularly vulnerable to micronutrient deficiencies [6,31]. A focus on maximizing nutrition during the second half of infancy is crucial as most of the growth faltering starts during this period [32,33], which may also have long-term and intergenerational consequences [34,35]. In the present study, we analyzed cobalamin and folate status, and explored its determinants among infants 6-11 months residing in the Bhaktapur municipality and peri-urban communities of Nepal.

\section{Methods}

\subsection{Study Site and Population}

Bhaktapur municipality is located $\sim 15 \mathrm{~km}$ east of Kathmandu, the capital city of Nepal. As per the last census it has a total population of 81,748 mostly belonging to the Newar ethnic groups and residing in 17,639 households, with 5053 children below five years of age. After the devastating earthquake on 25 April 2015, most of the households were damaged and most of the residents shifted to peri-urban areas of the municipality. Although most of the families are traditionally engaged in agriculture, other main incomes are from small-scale self-business, daily wage working and other labor. Ownership of land and houses are social indicators as most of the families that have migrated from other parts of Nepal, usually live in rented dwellings. Piped government supplies of drinking water to households or courtyards are common but supplies are limited to one hour per day or even fewer.

\subsection{Methods and Study Design}

We collected baseline blood samples from infants participating in a community-based, randomized, double blind clinical trial evaluating efficacy of daily cobalamin supplementation for one year on growth and cognitive development. A total of 600 children 6-11 months old with a length-for-age of less than minus one $z$-score were enrolled in the study. For the present study, results of the blood analyses are available only from the first 316 enrolled infants. Details of the study design and main outcomes of the 
study have been published elsewhere [36]. Apart from socio-economic and breastfeeding information, we also collected details on the use of micronutrient supplementation from the mothers during pregnancy. Infants with acute illness, severe systemic illness requiring hospitalization, severe malnutrition or taking $B$ vitamins at the time of enrolment were not included in study.

\subsection{Ethics}

The main study has obtained approval from the Nepal Health Research Council (NHRC, \#233/2014) in Nepal and from the Regional Committee for Medical and Health Research Ethics (REC \#2014/1528) in Norway and registered at clinicaltrials.gov (NCT02272842). Written informed consent from one of the parents (usually mother) was obtained. For illiterate parents, we took thumbprints in the presence of an impartial witness. In case of anemia (defined as hemoglobin $<11 \mathrm{~g} / \mathrm{dL}$ ), iron supplementation was given according to national guidelines. Implementation of the study was as stated in the latest version of the Helsinki Declaration.

\subsection{Blood Sampling and Biochemical Analyses}

Most blood samples (80\%) were taken at the study clinic after 12 noon, and collected from one of the cubital veins into heparinized polypropylene tubes (Sarstedt, Germany) which were protected from direct sunlight exposure. A total of $24 \%$ of the infants did not have any meal or snacks, during the day before blood sampling, whereas only $2 \%$ were not breastfed. The hemoglobin concentration was analyzed immediately following blood sampling with Hemocue (Ångelholm, Sweden), which was calibrated as per the guidelines defined by the manufacturer. The heparinized blood was centrifuged for $10 \mathrm{~min}$ at $700 \mathrm{~g}$ within $10 \mathrm{~min}$ after venipuncture and kept at $-196{ }^{\circ} \mathrm{C}$ liquid nitrogen located at the field site clinic. Plasma was separated, transferred into polypropylene vials (Eppendorf, Germany) and stored at $-80^{\circ} \mathrm{C}$ in Nepal until it was transferred to Norway on dry ice. Plasma tHcy and MMA were analyzed by gas chromatography-mass spectrometry (GC-MS) based on methylchloroformate derivatization [37]. The plasma concentrations of folate and cobalamin were determined using microbiological assays [38,39] based on a colistinsulfate-resistant strain of Lactobacillus leichmannii. The assay has been adapted to a microtiter plate format and is carried out by a robotic workstation. The between-day coefficient of variation ranged from 2-8\% for MMA and tHcy and was 5\% for both cobalamin and folate. All biochemical analyses were done at Bevital Laboratory, Bergen, Norway (www.bevital.no).

\subsection{Definitions}

The cut-off values for altitude adjusted (1400 m) anemia, low cobalamin, low folate, high MMA and high tHcy are as per the WHO/CDC guidelines: $11.3 \mathrm{~g} / \mathrm{dL},<148 \mathrm{pmol} / \mathrm{L},<10 \mathrm{nmol} / \mathrm{L},>0.28 \mu \mathrm{mol} / \mathrm{L}$, and $>10 \mu \mathrm{mol} / \mathrm{L}$, respectively [15,40]. Functional cobalamin deficiency is considered when MMA or tHcy are elevated. The combined indicator of cobalamin $\left(3 \mathrm{cB}_{12}\right)$ is calculated based on the three biomarkers (cobalamin, MMA and tHcy) as suggested by Fedosov et al. [18]. A score below $<-0.5$ is referred to as low cobalamin status. Underweight, stunting and wasting are defined as weight for age, length for age and weight for length z-scores below -2 z-score, respectively, as compared with WHO growth chart [41]. Breastfeeding patterns are categorized as exclusive, predominant, partial or none as per the definitions of Labbok and Krasovec and information were collected at the time of enrolment [42].

\subsection{Statistical Analyses}

Descriptive statistics such as means, medians, percentiles, interquartile ranges, standard deviations and 95\% confidence intervals (CI) were calculated for baseline characteristics and for plasma concentrations of cobalamin, folate, MMA, $\mathrm{tHcy}$, and $\mathrm{Hb}$, as well as the combined indicator $3 \mathrm{cB}_{12}$. To identify determinants for cobalamin and biomarker status, we used the $3 \mathrm{cB}_{12}$ and $\log$-transformed tHcy, MMA and cobalamin concentrations as the dependent variables in multiple linear regression models. Candidate variables for these regression models are those listed in Table 1 . We selected the 
variables in a purposeful manual selection procedure as described elsewhere [43]. In short, all variables were assessed in crude models, variables that were significant at a 0.2 level were included in a more saturated model. The candidate variables that were not significant in the crude model were then included in this multiple model one at a time. If the variables became significant, they were retained in the model. After the final step of the variable selection process, only variables that were significant on the 0.05 level were kept in the model. We decided a priori to include age of the child (in months) in all regression models. Statistical analyses were undertaken using Stata ${ }^{\circledR}$, version 15 (STATA Corp, Houston, TX, USA).

\section{Results}

\subsection{General Characteristics and Breast and Complementary Feeding Practices}

The mean age of the 316 enrolled infants was 8.3 months and $53 \%$ were male. One in every second family lived in a rented house and 50\% were living in joint families. Most of the children were delivered at health centers (95\%) with normal vaginal delivery (74\%). At birth, 17\% of the children had low birth weight (birth weight <2500 g) (Table 1). Almost all mothers $(96 \%)$ had regular antenatal check-ups and took iron supplementation which usually also contained folic acid. Calcium supplementation during pregnancy is also universal practice in our setting and usually starts from the second trimester.

Most of the infants (85\%) received breast milk within $24 \mathrm{~h}$ of delivery (56\% within one hour), but the prevalence of exclusive breastfeeding at 3 and 6 months was only $43 \%$ and $10 \%$, respectively. Early introduction of homemade cereals (lito) or Cerelac (Nestlé) was a common practice as $40 \%$ of infants were given these foods by 3 months of age but this is recommended only after 6 months of age. An Ayurvedic liquid (Janamghuti) was also given to 54\% of infants, often within 3 months after delivery. One third of the infants were stunted (<-2 z-score), whereas the prevalence of underweight infants was $19 \%$ (Table 1).

Table 1. Baseline characteristics of 316 infants participating in a clinical trial on vitamin B12 in Bhaktapur Nepal.

\begin{tabular}{|c|c|c|c|}
\hline Characteristics & $N(\%)$ & Mean & SD \\
\hline Age, months & & 8.3 & 1.9 \\
\hline First born child & $151(48)$ & & \\
\hline Male child & $167(53)$ & & \\
\hline Home delivery & $15(5)$ & & \\
\hline Birth weight, gm ${ }^{1}$ & & 2813 & 482 \\
\hline Low birth weight (<2500 gm) & $52(17)$ & & \\
\hline \multicolumn{4}{|l|}{ Demographic features } \\
\hline Illiterate or up to grade 5 education of mother & $128(41)$ & & \\
\hline Illiterate or up to grade 5 education of father & $118(37)$ & & \\
\hline Not working mother or engaging only in agricultural work & $197(62)$ & & \\
\hline Mother's age & & 27.4 & 4.7 \\
\hline Family staying in own house & $161(51)$ & & \\
\hline Family staying in joint family & $159(50)$ & & \\
\hline Family having own land & $145(46)$ & & \\
\hline \multicolumn{4}{|l|}{ Breastfeeding status } \\
\hline Exclusive breastfeeding for 3 months or more ${ }^{2}$ & $137(43)$ & & \\
\hline Exclusive breastfeeding for 6 months & $33(10)$ & & \\
\hline \multicolumn{4}{|l|}{ Nutritional status } \\
\hline Underweight (weight for age $<-2 z$-score) & $62(19)$ & & \\
\hline Stunting (length for age $<-2 z$-score) & $106(33)$ & & \\
\hline Wasting (weight for length $<-2 z$-score) & $13(6)$ & & \\
\hline Maternal undernutrition ${ }^{3}$ & $34(6)$ & & \\
\hline
\end{tabular}

${ }^{1}$ Among 302 newborns from whom birth weights were available; ${ }^{2}$ exclusive breastfeeding defined as: the child is given breast milk only, no water or complementary foods, except for medicines. ${ }^{3} \mathrm{BMI}<18.5 \mathrm{~kg} / \mathrm{m}^{2}$. 


\subsection{Plasma Cobalamin, Folate, $M M A$, tHcy and $3 c B_{12}$}

The geometric mean (95\% CI) concentration of cobalamin, folate, tHcy and MMA were 271.6 (257.8-286.2) pmol/L, 61 (59-64) nmol/L, 10.8 (10.3-11.4) $\mu \mathrm{mol} / \mathrm{L}$, and $0.50(0.46-0.55) \mu \mathrm{mol} / \mathrm{L}$ respectively. The mean (SD) $3 \mathrm{cB}_{12}$ was $-0.70(0.84)$. The percentile distributions of these bio-markers are presented in Table 2, and the association between these biomarkers and age of infants are depicted in Figure 1. Except for the plasma folate concentrations which were higher $(72.5 \mathrm{vs} .62 .9 \mathrm{nmol} / \mathrm{L}, p=0.002)$ in the fasting samples (no meal or snacks prior to the blood sampling), none of other bio-markers were different according to the history of food/snack consumption before blood sampling. Based on plasma cobalamin concentration $<148 \mathrm{pmol} / \mathrm{L}$, only $11 \%$ of infants were cobalamin-deficient, whereas $24 \%$ had cobalamin concentration between 148-221 pmol/L. None of the infants were found to be folate-deficient when using the conventional cut-off value of folate concentration $(<10 \mathrm{nmol} / \mathrm{L})$. The folate status was found to be very good in this population ranging from 20.7 to $150.8 \mathrm{nmol} / \mathrm{L}$. Three-fourths of the infants had elevated MMA levels $(>0.28 \mu \mathrm{mol} / \mathrm{L})$, while $53 \%$ had tHcy $>10 \mu \mathrm{mol} / \mathrm{L}$ indicating functional cobalamin deficiency (Table 3). However, based on the $3 \mathrm{cB}_{12}, 58 \%$ of the infants had low cobalamin status. The mean $\mathrm{Hb}$ was $10.7 \mathrm{~g} / \mathrm{dL}$, and anemia was found in $61 \%$, but mostly with a mild degree of severity.
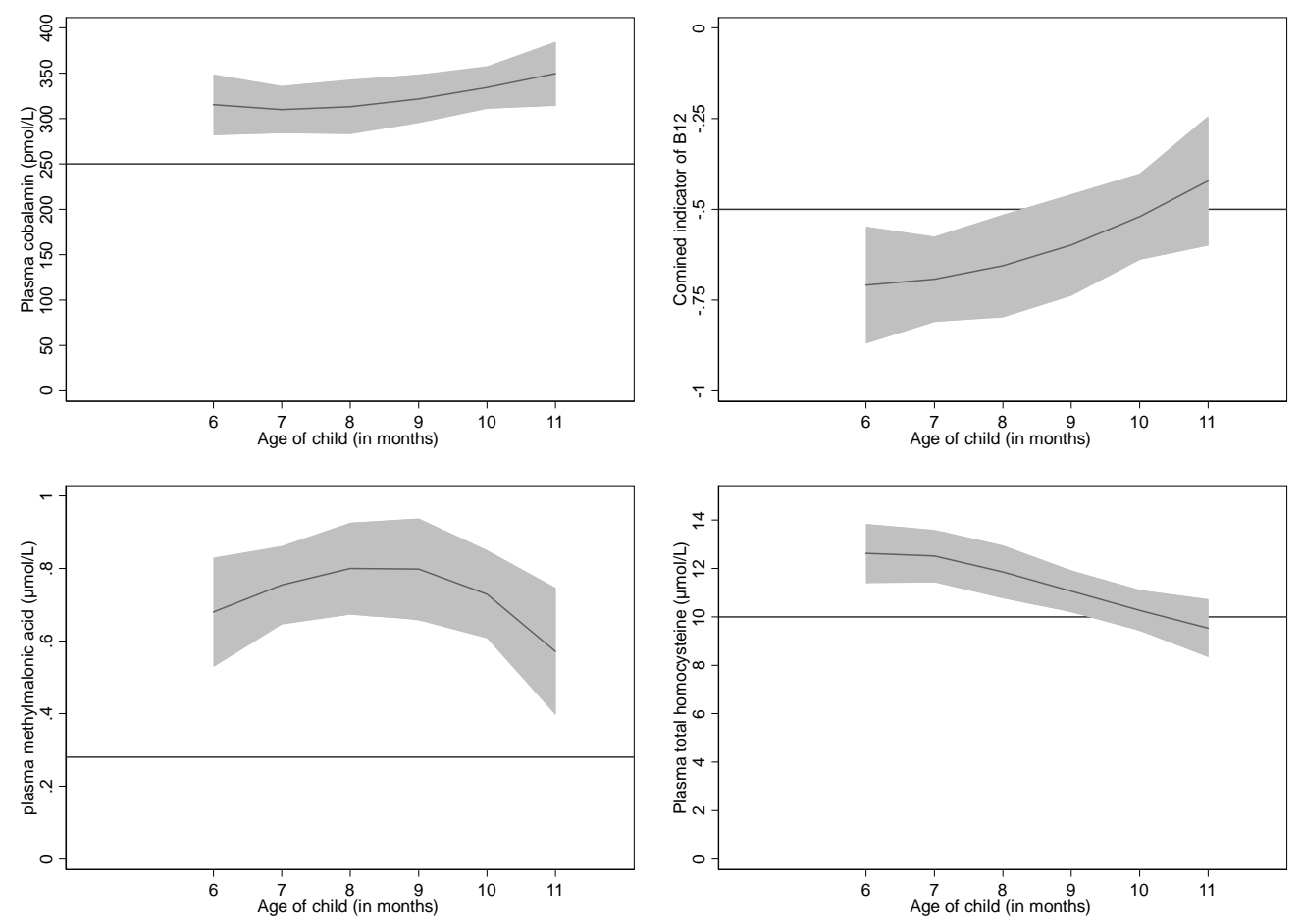

Figure 1. Concentrations of plasma cobalamin, combined indicator $\left(3 \mathrm{cB}_{12}\right)$, methylmalonic acid and total homocysteine by age among 316 breastfed infants in Bhaktapur, Nepal. The $Y$ axis is the concentration of the biomarker and the $X$ axis is the age of the infant (month). The shaded area represents the $95 \% \mathrm{CI}$ of the depicted association. The horizontal lines indicate commonly used cut-offs for the different biomarkers $\left(250 \mathrm{pmol} / \mathrm{L}\right.$ for cobalamin, -0.5 for $3 \mathrm{cB}_{12}, 0.28 \mu \mathrm{mol} / \mathrm{L}$ for MMA, and $10 \mu \mathrm{mol} / \mathrm{L}$ for tHcy). 
Table 2. Mean and percentile distributions of cobalamin, folate, hemoglobin, total homocysteine (tHcy), $3 \mathrm{cB}_{12}$ and methylmalonic acid(MMA) concentrations among 316 infants participating in a clinical trial on vitamin $B_{12}$ in Bhaktapur Nepal.

\begin{tabular}{|c|c|c|c|c|c|c|}
\hline Mean/Centile & Cobalamin (pmol/L) & Folate (nmol/L) & tHcy $(\mu \mathrm{mol} / \mathrm{L})$ & MMA ( $\mu \mathrm{mol} / \mathrm{L})$ & $3 \mathrm{cB}_{12}$ & $\mathrm{Hb}(\mathrm{g} / \mathrm{dL})$ \\
\hline & 304 & 65 & 12.1 & 0.74 & -0.70 & 10.7 \\
\hline Mean (SD) & $(152)$ & (23) & (6.5) & $(0.86)$ & $(0.84)$ & (0.9) \\
\hline $5 \%$ & 124 & 33 & 5.6 & 0.15 & -2.2 & 9.4 \\
\hline $25 \%$ & 201 & 48 & 7.8 & 0.27 & -1.2 & 10 \\
\hline $50 \%$ & 272 & 62 & 10.3 & 0.48 & -0.64 & 10.6 \\
\hline $75 \%$ & 364 & 77 & 14.2 & 0.83 & -0.13 & 11.4 \\
\hline $95 \%$ & 601 & 112 & 24.8 & 2.43 & 0.62 & 12.3 \\
\hline
\end{tabular}

$3 \mathrm{cB}_{12}=$ combined indicator of vitamin $\mathrm{B}_{12}$ status including 3 biomarkers (cobalamin, MMA, and tHcy), tHcy = total homocysteine, $\mathrm{MMA}=$ methylmalonic acid and $\mathrm{Hb}=$ hemoglobin concentration.

Table 3. Prevalence of cobalamin and folate deficiency and anemia among 316 infants participating in a clinical trial in Bhaktapur, Nepal.

\begin{tabular}{lcc}
\hline Definition & Cut off & Prevalence (95\% CI) \\
\hline Anemia & $<11 \mathrm{gm} / \mathrm{dL}$ & $61 \%(55-66)$ \\
Altitude adjusted anemia & $<11.3 \mathrm{gm} / \mathrm{dL}$ & $70 \%(65-75)$ \\
Cobalamin deficiency & $<148 \mathrm{pmol} / \mathrm{L}$ & $11 \%(7-14)$ \\
Marginal cobalamin deficiency & $148-221 \mathrm{pmol} / \mathrm{L}$ & $24 \%(19-29)$ \\
Combined indicator of $\mathrm{B}_{12}\left(3_{\mathrm{cB}} \mathrm{B}_{12}\right)^{2}$ & $<-0.5$ & $58 \%(53-64)$ \\
Folate deficiency & $<10 \mathrm{nmol} / \mathrm{L}$ & 0 \\
High total homocysteine $^{2}$ & $>10 \mu \mathrm{mol} / \mathrm{L}$ & $53 \%(47-58)$ \\
High methylmalonic acid $^{2}$ & $>0.28 \mu \mathrm{mol} / \mathrm{L}$ & $75 \%(70-79)$ \\
\hline
\end{tabular}

${ }^{1}$ based on the combined indicator of vitamin $B_{12}$ status including 3 biomarkers (cobalamin, MMA, and tHcy) as suggested by Fedosov et al. [18]. ${ }^{2}$ both conditions indicate functional $\mathrm{B}_{12}$ deficiencies.

\subsection{Determinants for Cobalamin Status Biomarkers}

Adjusted (and back-transformed when relevant) regression coefficient for $3 \mathrm{cB}_{12}, \mathrm{tHcy}, \mathrm{MMA}$, and cobalamin derived from multiple linear regression analyses are presented in Table 4 . Concentrations of tHcy decreased with increasing age (in months) of the infants. Cobalamin concentration and $3 \mathrm{cB}_{12}$ increased with age whereas there were no significant association between age and MMA. Infants from a family staying on rent had lower $3 \mathrm{cB}_{12}$, and higher MMA and tHcy than those from families staying in their own property. Higher tHcy concentrations were also found among infants who were exclusively breastfed for three months or more. Stunted infants had higher MMA concentrations, whereas underweight infants had higher plasma cobalamin concentrations.

Table 4. Determinants for the combined cobalamin indicator $\left(3 \mathrm{cB}_{12}\right)^{1}$, total homocysteine (tHcy), methylmalonic acid (MMA), and cobalamin concentrations according to demographic household parameters and nutritional status by multiple linear regression among 316 infants participating in a clinical trial in Bhaktapur, Nepal ${ }^{2}$.

\begin{tabular}{|c|c|c|c|c|}
\hline \multirow{2}{*}{ Independent Variables } & \multicolumn{4}{|c|}{ Dependent Variables } \\
\hline & $3 \mathrm{cB}_{12}$ & tHcy & MMA & Cobalamin \\
\hline Age of child (month) & $0.06(0.01,0.11)$ & $0.93(0.89,0.96)$ & $0.99(0.93,1.06)$ & $1.05(1.01,1.10)$ \\
\hline Family not staying in own house & $-0.19(-0.39,0.01)$ & $1.17(1.01,1.36)$ & $1.43(1.10,1.85)$ & \\
\hline Age of Mother (year) & $0.02(0.02,0.04)$ & $0.98(0.97,0.99)$ & & \\
\hline Father completed education $\leq 5$ year & $0.22(0.03,0.41)$ & $0.85(0.74,0.98)$ & & \\
\hline Excl. breastfeeding $\geq 3$ months & & $1.16(1.01,1.35)$ & & \\
\hline Underweight (weight for age $<-2 z$-score) & & & & $1.29(1.07,1.56)$ \\
\hline Stunting (length for age $<-2 z$-score) & & & $1.47(1.12,1.93)$ & \\
\hline \multicolumn{5}{|c|}{$\begin{array}{l}{ }^{1} \text { Combined cobalamin indicator that consists of } 3 \text { biomarkers (cobalamin, MMA, and tHcy) [18]. }{ }^{2} \text { Coefficients } \\
\text { from by multiple linear regression analysis, MMA, tHcy, and cobalamin were log-transformed in the regression } \\
\text { analyses. The regression coefficients and the confidence intervals were back transformed so that the coefficients } \\
\text { represent the fold increase in the dependent variable for each unit increase in the independent variable. } 3 \mathrm{cB}_{12} \text { was } \\
\text { not log-transformed. For example, the regression coefficient for "Stunting" on MMA is } 1.47 \text { which means that the } \\
\text { stunted children had a MMA concentration that was on an average } 47 \% \text { higher than the non-stunted children. }\end{array}$} \\
\hline
\end{tabular}




\section{Discussion}

In this cross-sectional analysis consisting of 6-11 months old breastfed infants included over a period of 12 months, we observed cobalamin deficiencies ranging from $11-75 \%$ depending upon the indicator that was used. None of the infants had folate deficiency. Based on the combined biomarker $\left(3 \mathrm{cB}_{12}\right), 58 \%$ had low cobalamin status. One in every second infant had high tHcy or MMA suggesting that functional cobalamin deficiency is wide-spread. It should be noted that for cobalamin and the functional markers, there are no well-established cutoff values in infants. Various cutoffs and combinations have been suggested. Bjørke-Monsen et al used a cutoff of $6.5 \mu \mathrm{mol} / \mathrm{L}$ tHcy which was the 95th percentile in infants who had received an injection of vitamin $B_{12}$ [44]. According to this definition, $77 \%$ of our infants were functional cobalamin deficient. In a review from 2003 , the functional biomarker concentrations from almost 30 studies in young children worldwide were presented [14]. The concentrations of the biomarkers presented in this current study were not very different from those reported from the studies included in this review. Nor were the concentrations from more recent studies in infant populations in Norway [26,45]. In the above-mentioned review and in Norwegian studies, however, none of the infant populations had a mean tHcy $>10 \mu \mathrm{mol} / \mathrm{L}$ while in our study the geometric mean tHcy was $10.8 \mu \mathrm{mol} / \mathrm{L}$. Equally high tHcy concentrations were observed in other infant and women populations of India and Nepal [6,8]. In these studies, plasma cobalamin and MMA also explained a substantial part of the variability of tHcy. However, the relatively high tHcy compared to MMA concentrations suggests that there are other causes of elevated tHcy (in addition to poor cobalamin status). If this is the case, it will also overestimate the true prevalence when using combined approaches such as those suggested by Fedosov et al. [18] or by Stabler et al. [46].

Our findings of excellent folate status in this population may partly be explained by high iron/folic acid intake by mothers during pregnancy, breastfeeding and the availability of folate in vegetarian foods given to infants $[30,47]$. Similar findings of high folate status but low cobalamin were found in a recent study from Nepal among 6-23 months old children from Kapilvastu and Achham districts [31], and in our previous studies from the same community among children [8,47] and mothers [7]. In these studies, folate deficiency was also uncommon, but cobalamin deficiency based on low plasma cobalamin ranged from $17-41 \%$. Most of the weaning foods in Nepal are vegetarian/plant-based [48,49] containing fair amounts of folate, particularly in legumes, fruits and nuts. These foods combined with good coverage of folic acid and iron supplementation during pregnancy [30], probably explain the high folate status in this population.

Cobalamin and folate are both essential for erythropoiesis and deficiency may lead to anemia, [50]. Although the prevalence of anemia in our study is quite high, we did not find any association with any of the biomarkers in the regression analyses; a similar observation has previously been made in adult populations [15,51]. Adequate complementary feeding both in terms of quality and quantity is required for infants after six months of age to fulfill their micronutrient requirements [21,32]. In a study in Norwegian infants with a birth weight between 2 to $3 \mathrm{~kg}$, exclusive breastfeeding for at least 3 months was associated with an increased risk of cobalamin deficiency [52]. In our study, children who were exclusively breasted for more than 3 months had significantly higher tHcy concentrations than those who were not. Our finding supports those who argue for maternal $B_{12}$ supplementation, particularly if the mother is vegan and exclusively breastfeeding [53]. However, none of the other vitamin $B_{12}$ indices were associated with exclusive breastfeeding in our study. This could be an indication that plasma tHcy is an unspecific marker of $B_{12}$ status, and that the increase in tHcy also could be due to other causes for example deficiencies in other nutrients, such as vitamin $B_{2}$ or $B_{6}$ [54]. Our findings of associations of house-ownership with $3 \mathrm{cB}_{12}$ and tHcy suggests that socio-economic status also plays an important role for cobalamin status among infants. Compared with families who are renting, families having their own house mainly belong to the local Newar ethnic groups, and probably have a better socio-economic status. Another study also found that intake of micronutrients, including cobalamin among infants was associated with higher socio-economic status of the family [55]. An analysis based on the WHO/UNICEF CORE indicators on infant and young child feeding in South Asia found poor 
scores on minimum dietary diversity, acceptable diet or meal frequency [56]. Although we did not analyze these CORE infant feeding indicators specifically, previous studies from the same community and in Nepal found that intake of micronutrients including cobalamin are often poor $[30,57,58]$.

The main strength of our study is the relatively large community-based sample of breastfed 6-11 months old infants who were screened by clinical examination for acute or chronic illnesses by a physician. Data on cobalamin and folate status covering a panel of biomarkers particularly from healthy infants from this age group are rare. Available published data are based on limited markers in children with a wide age range (6-23 months) [31] or from clinical populations [8,59]. Furthermore, we also collected detailed information on antenatal micronutrient supplementation, which may influence cobalamin and folate status of the offspring [60].

We also recognize some limitations of our study. Due to our enrolment criteria in the main study, our samples are based on infants with length-for-age $z$-scores of $<-1$, which may limit the generalizability of our findings. This was also reflected in the high prevalence of stunting $(33 \%)$, in comparison to the 17 to $20 \%$ range in this age group in the last demographic survey of Nepal [30]. However, except MMA, none of other indices were associated with stunting. Due to the rapid physiological changes and introduction of different weaning foods, it is also challenging to find acceptable age specific cut-off values for markers of folate and cobalamin during the second half of infancy [14].

\section{Conclusions}

Based on measurement of functional markers of cobalamin status, such as tHcy and MMA and the combined cobalamin indicator $\left(3 \mathrm{cB}_{12}\right)$ more than $50 \%$ of the infants with length for age $<-1 z$-score may be cobalamin-deficient, which is probably due to sub-optimal maternal nutritional status during pregnancy and lactation or predominantly vegetarian complementary feeding. It is important to identify immediate and long-term consequences of poor cobalamin status during infancy.

Author Contributions: T.A.S., L.S., M.H., I.K. and R.K.C. designed the study; R.K.C., M.U., S.R. and M.S. conducted the research and responsible for field implementation and data collection; P.M.U. and A.U. analyzed the blood samples and interpreted the results; R.K.C. and T.A.S. had primary responsibility for the final content. All authors read and approved the final manuscript.

Acknowledgments: We thank children and family of Bhaktapur who participated in this study and Prakash S Shrestha and all the staff at Child Health Research Project, Department of Child Health, Tribhuvan University, Kathmandu, Nepal. We thank, Shyam Dhaubhadel, founder of Siddhi Memorial Hospital in Bhaktapur and staff for their cooperation.

Conflicts of Interest: The authors declared no conflict of interest.

\section{List of Abbreviations}

MMA, methylmalonic acid; tHcy- total homocysteine; $3 \mathrm{cB}_{12}$-combined indicator of $\mathrm{B}_{12}$.

\section{References}

1. Black, M.M. Effects of vitamin B12 and folate deficiency on brain development in children. Food Nutr. Bull. 2008, 29, S126-S131. [CrossRef] [PubMed]

2. Moore, E.; Mander, A.; Ames, D.; Carne, R.; Sanders, K.; Watters, D. Cognitive impairment and vitamin B12: A review. Int. Psychogeriatr. 2012, 24, 541-556. [CrossRef] [PubMed]

3. Obeid, R.; Murphy, M.; Sole-Navais, P.; Yajnik, C. Cobalamin Status from Pregnancy to Early Childhood: Lessons from Global Experience. Adv. Nutr. 2017, 8, 971-979. [CrossRef] [PubMed]

4. Allen, L.H. Causes of vitamin B12 and folate deficiency. Food Nutr. Bull. 2008, 29, S20-S34; discussion S35-S37. [CrossRef] [PubMed]

5. Samuel, T.M.; Duggan, C.; Thomas, T.; Bosch, R.; Rajendran, R.; Virtanen, S.M.; Srinivasan, K.; Kurpad, A.V. Vitamin B(12) intake and status in early pregnancy among urban South Indian women. Ann. Nutr. Metab. 2013, 62, 113-122. [CrossRef] [PubMed] 
6. Taneja, S.; Bhandari, N.; Strand, T.A.; Sommerfelt, H.; Refsum, H.; Ueland, P.M.; Schneede, J.; Bahl, R.; Bhan, M.K. Cobalamin and folate status in infants and young children in a low-to-middle income community in India. Am. J. Clin. Nutr. 2007, 86, 1302-1309. [CrossRef] [PubMed]

7. Chandyo, R.K.; Ulak, M.; Sommerfelt, H.; Schneede, J.; Ueland, P.M.; Strand, T.A. Nutritional Intake and Status of Cobalamin and Folate among Non-Pregnant Women of Reproductive Age in Bhaktapur, Nepal. Nutrients 2016, 8. [CrossRef] [PubMed]

8. Ulak, M.; Chandyo, R.K.; Adhikari, R.K.; Sharma, P.R.; Sommerfelt, H.; Refsum, H.; Strand, T.A. Cobalamin and folate status in 6 to 35 months old children presenting with acute diarrhea in Bhaktapur, Nepal. PLOS ONE 2014, 9, e90079. [CrossRef] [PubMed]

9. Strand, T.A.; Taneja, S.; Ueland, P.M.; Refsum, H.; Bahl, R.; Schneede, J.; Sommerfelt, H.; Bhandari, N. Cobalamin and folate status predicts mental development scores in North Indian children 12-18 mo of age. Am. J. Clin. Nutr. 2013, 97, 310-317. [CrossRef] [PubMed]

10. Strand, T.A.; Taneja, S.; Kumar, T.; Manger, M.S.; Refsum, H.; Yajnik, C.S.; Bhandari, N. Vitamin B-12, folic acid, and growth in 6- to 30-month-old children: A randomized controlled trial. Pediatrics 2015, 135, e918-e926. [CrossRef] [PubMed]

11. Kvestad, I.; Hysing, M.; Shrestha, M.; Ulak, M.; Thorne-Lyman, A.L.; Henjum, S.; Ueland, P.M.; Midttun, O.; Fawzi, W.; Chandyo, R.K.; et al. Vitamin B-12 status in infancy is positively associated with development and cognitive functioning 5 y later in Nepalese children. Am. J. Clin. Nutr. 2017, 105, 1122-1131. [CrossRef] [PubMed]

12. Roth, C.; Magnus, P.; Schjolberg, S.; Stoltenberg, C.; Suren, P.; McKeague, I.W.; Davey Smith, G.; Reichborn-Kjennerud, T.; Susser, E. Folic acid supplements in pregnancy and severe language delay in children. JAMA 2011, 306, 1566-1573. [CrossRef] [PubMed]

13. Suren, P.; Roth, C.; Bresnahan, M.; Haugen, M.; Hornig, M.; Hirtz, D.; Lie, K.K.; Lipkin, W.I.; Magnus, P.; Reichborn-Kjennerud, T.; et al. Association between maternal use of folic acid supplements and risk of autism spectrum disorders in children. JAMA 2013, 309, 570-577. [CrossRef] [PubMed]

14. Bjorke Monsen, A.L.; Ueland, P.M. Homocysteine and methylmalonic acid in diagnosis and risk assessment from infancy to adolescence. Am. J. Clin. Nutr. 2003, 78, 7-21. [CrossRef] [PubMed]

15. Refsum, H.; Yajnik, C.S.; Gadkari, M.; Schneede, J.; Vollset, S.E.; Orning, L.; Guttormsen, A.B.; Joglekar, A.; Sayyad, M.G.; Ulvik, A.; et al. Hyperhomocysteinemia and elevated methylmalonic acid indicate a high prevalence of cobalamin deficiency in Asian Indians. Am. J. Clin. Nutr. 2001, 74, 233-241. [CrossRef] [PubMed]

16. Hannibal, L.; Lysne, V.; Bjorke-Monsen, A.L.; Behringer, S.; Grunert, S.C.; Spiekerkoetter, U.; Jacobsen, D.W.; Blom, H.J. Biomarkers and Algorithms for the Diagnosis of Vitamin B12 Deficiency. Front. Mol. Biosci. 2016, 3, 27. [CrossRef] [PubMed]

17. Green, R.; Allen, L.H.; Bjorke-Monsen, A.L.; Brito, A.; Gueant, J.L.; Miller, J.W.; Molloy, A.M.; Nexo, E.; Stabler, S.; Toh, B.H.; et al. Vitamin B12 deficiency. Nat. Rev. Dis. Primers 2017, 3, 17040. [CrossRef] [PubMed]

18. Fedosov, S.N.; Brito, A.; Miller, J.W.; Green, R.; Allen, L.H. Combined indicator of vitamin B12 status: Modification for missing biomarkers and folate status and recommendations for revised cut-points. Clin. Chem. Lab. Med. 2015, 53, 1215-1225. [CrossRef] [PubMed]

19. WHO/FAO (World Health Organization/Food and Agriculture Organization). Vitamin and Mineral Requirements in Human Nutrition: Report of a Joint FAO/WHO Expert Consultation, Bangkok, Thailand, 21-30 September 1998; WHO/FAO: Geneva, Switzerland, 2004.

20. NAP; Institute of Medicine. Vitamin B12. In Dietary Reference Intakes for Thiamin, Riboflavin, Niacin, Vitamin B6, Folate, Vitamin B12, Pantothenic Acid, Biotin, and Choline; National Academy Press: Washington, DC, USA, 2000; pp. 306-356.

21. Greibe, E.; Lildballe, D.L.; Streym, S.; Vestergaard, P.; Rejnmark, L.; Mosekilde, L.; Nexo, E. Cobalamin and haptocorrin in human milk and cobalamin-related variables in mother and child: A 9-mo longitudinal study. Am. J. Clin. Nutr. 2013, 98, 389-395. [CrossRef] [PubMed]

22. Allen, L.H. B vitamins in breast milk: Relative importance of maternal status and intake, and effects on infant status and function. Adv. Nutr. 2012, 3, 362-369. [CrossRef] [PubMed]

23. Koc, A.; Kocyigit, A.; Soran, M.; Demir, N.; Sevinc, E.; Erel, O.; Mil, Z. High frequency of maternal vitamin B12 deficiency as an important cause of infantile vitamin B12 deficiency in Sanliurfa province of Turkey. Eur. J. Nutr. 2006, 45, 291-297. [CrossRef] [PubMed] 
24. Roumeliotis, N.; Dix, D.; Lipson, A. Vitamin B(12) deficiency in infants secondary to maternal causes. Can. Med. Assoc. J. 2012, 184, 1593-1598. [CrossRef] [PubMed]

25. Finkelstein, J.L.; Kurpad, A.V.; Thomas, T.; Srinivasan, K.; Duggan, C. Vitamin B12 status in pregnant women and their infants in South India. Eur. J. Clin. Nutr. 2017, 71, 1046-1053. [CrossRef] [PubMed]

26. Hay, G.; Trygg, K.; Whitelaw, A.; Johnston, C.; Refsum, H. Folate and cobalamin status in relation to diet in healthy 2-y-old children. Am. J. Clin. Nutr. 2011, 93, 727-735. [CrossRef] [PubMed]

27. Johnson, M.A. If high folic acid aggravates vitamin B12 deficiency what should be done about it? Nutr. Rev. 2007, 65, 451-458. [CrossRef] [PubMed]

28. Paul, L.; Selhub, J. Interaction between excess folate and low vitamin B12 status. Mol. Asp. Med. 2017, 53, 43-47. [CrossRef] [PubMed]

29. Rasmussen, S.A.; Fernhoff, P.M.; Scanlon, K.S. Vitamin B12 deficiency in children and adolescents. J. Pediatr. 2001, 138, 10-17. [CrossRef] [PubMed]

30. New ERA; Ministry of Health, Nepal; ICF. Nepal Demographic and Health Survey 2016: Key Indicators; Ministry of Health: Kathmandu, Nepal, 2017.

31. Ng'eno, B.N.; Perrine, C.G.; Whitehead, R.D.; Subedi, G.R.; Mebrahtu, S.; Dahal, P.; Jefferds, M.E. High Prevalence of Vitamin B12 Deficiency and No Folate Deficiency in Young Children in Nepal. Nutrients 2017, 9. [CrossRef] [PubMed]

32. WHO. Indicators for Assesing Infant and Young Child Feeding Practices. In Proceedings of the Consensus Meeting, Washington, DC, USA, 6-8 November 2007.

33. Cusick, S.E.; Georgieff, M.K. The Role of Nutrition in Brain Development: The Golden Opportunity of the "First 1000 Days". J. Pediatr. 2016, 175, 16-21. [CrossRef] [PubMed]

34. Yajnik, C.S.; Deshmukh, U.S. Maternal nutrition, intrauterine programming and consequential risks in the offspring. Rev. Endocr. Metab. Disord. 2008, 9, 203-211. [CrossRef] [PubMed]

35. Abeshu, M.A.; Lelisa, A.; Geleta, B. Complementary Feeding: Review of Recommendations, Feeding Practices, and Adequacy of Homemade Complementary Food Preparations in Developing Countries-Lessons from Ethiopia. Front. Nutr. 2016, 3, 41. [CrossRef] [PubMed]

36. Strand, T.A.; Ulak, M.; Chandyo, R.K.; Kvestad, I.; Hysing, M.; Shrestha, M.; Basnet, S.; Ranjitkar, S.; Shrestha, L.; Shrestha, P.S. The effect of vitamin B12 supplementation in Nepalese infants on growth and development: Study protocol for a randomized controlled trial. Trials 2017, 18, 187. [CrossRef] [PubMed]

37. Windelberg, A.; Arseth, O.; Kvalheim, G.; Ueland, P.M. Automated assay for the determination of methylmalonic acid, total homocysteine, and related amino acids in human serum or plasma by means of methylchloroformate derivatization and gas chromatography-mass spectrometry. Clin. Chem. 2005, 51, 2103-2109. [CrossRef] [PubMed]

38. Molloy, A.M.; Scott, J.M. Microbiological assay for serum, plasma, and red cell folate using cryopreserved, microtiter plate method. Methods Enzymol. 1997, 281, 43-53. [PubMed]

39. Kelleher, B.P.; Walshe, K.G.; Scott, J.M.; O’Broin, S.D. Microbiological assay for vitamin B12 with use of a colistin-sulfate-resistant organism. Clin. Chem. 1987, 33, 52-54. [PubMed]

40. WHO. Serum and Red Blood Cell Folate Concentrations for Assessing Folate Status in Population. Vitamin and Mineral Nutrition Information System; World Health Organization: Geneva, Switzerland, 2012.

41. WHO. World Health Organization. Anthro 2005, Beta Version, 17 February 2006: Software for Assessing Growth and Development of the World's Children; WHO: Geneva, Switzerland, 2006; Available online: http:/ / www. who.int/childgrowth/software/en/ (accessed on 2 February 2016).

42. Labbok, M.; Krasovec, K. Toward consistency in breastfeeding definitions. Stud. Fam. Plan. 1990, 21, $226-230$. [CrossRef]

43. Hosmer, D.W.; Lemeshow, S. Applied Logistic Regression; John Wiley \& Sons Inc.: New York, NY, USA, 2000.

44. Bjorke-Monsen, A.L.; Torsvik, I.; Saetran, H.; Markestad, T.; Ueland, P.M. Common metabolic profile in infants indicating impaired cobalamin status responds to cobalamin supplementation. Pediatrics 2008, 122, 83-91. [CrossRef] [PubMed]

45. Torsvik, I.; Ueland, P.M.; Markestad, T.; Bjorke-Monsen, A.L. Cobalamin supplementation improves motor development and regurgitations in infants: Results from a randomized intervention study. Am. J. Clin. Nutr. 2013, 98, 1233-1240. [CrossRef] [PubMed]

46. Stabler, S.P. Vitamin B12 deficiency. N. Engl. J. Med. 2013, 368, 2041-2042. [CrossRef] [PubMed] 
47. Ulak, M.; Chandyo, R.K.; Thorne-Lyman, A.L.; Henjum, S.; Ueland, P.M.; Midttun, O.; Shrestha, P.S.; Fawzi, W.W.; Graybill, L.; Strand, T.A. Vitamin Status among Breastfed Infants in Bhaktapur, Nepal. Nutrients 2016, 8, 149. [CrossRef] [PubMed]

48. Na, M.; Aguayo, V.M.; Arimond, M.; Dahal, P.; Lamichhane, B.; Pokharel, R.; Chitekwe, S.; Stewart, C.P. Trends and predictors of appropriate complementary feeding practices in Nepal: An analysis of national household survey data collected between 2001 and 2014. Matern. Child Nutr. 2017. [CrossRef] [PubMed]

49. Ulak, M.; Chandyo, R.K.; Mellander, L.; Shrestha, P.S.; Strand, T.A. Infant feeding practices in Bhaktapur, Nepal: A cross-sectional, health facility based survey. Int. Breastfeed. J. 2012, 7, 1. [CrossRef] [PubMed]

50. Koury, M.J.; Ponka, P. New insights into erythropoiesis: The roles of folate, vitamin B12, and iron. Annu. Rev. Nutr. 2004, 24, 105-131. [CrossRef] [PubMed]

51. Bondevik, G.T.; Schneede, J.; Refsum, H.; Lie, R.T.; Ulstein, M.; Kvale, G. Homocysteine and methylmalonic acid levels in pregnant Nepali women. Should cobalamin supplementation be considered? Eur. J. Clin. Nutr. 2001, 55, 856-864. [CrossRef] [PubMed]

52. Torsvik, I.K.; Ueland, P.M.; Markestad, T.; Midttun, O.; Bjorke Monsen, A.L. Motor development related to duration of exclusive breastfeeding, B vitamin status and B12 supplementation in infants with a birth weight between 2000-3000 g, results from a randomized intervention trial. BMC Pediatr. 2015, 15, 218. [CrossRef] [PubMed]

53. Finkelstein, J.L.; Layden, A.J.; Stover, P.J. Vitamin B-12 and Perinatal Health. Adv. Nutr. 2015, 6, 552-563. [CrossRef] [PubMed]

54. Manios, Y.; Moschonis, G.; Dekkers, R.; Mavrogianni, C.; Grammatikaki, E.; van den Heuvel, E. Vitamin B2, vitamin B12 and total homocysteine status in children and their associations with dietary intake of B-vitamins from different food groups: The Healthy Growth Study. Eur. J. Nutr. 2017, 56, 321-331. [CrossRef] [PubMed]

55. Wong, A.Y.; Chan, E.W.; Chui, C.S.; Sutcliffe, A.G.; Wong, I.C. The phenomenon of micronutrient deficiency among children in China: A systematic review of the literature. Public Health Nutr. 2014, 17, 2605-2618. [CrossRef] [PubMed]

56. Senarath, U.; Dibley, M.J. Complementary feeding practices in South Asia: Analyses of recent national survey data by the South Asia Infant Feeding Research Network. Matern. Child Nutr. 2012, 8 (Suppl. 1), 5-10. [CrossRef] [PubMed]

57. Khanal, V.; Sauer, K.; Zhao, Y. Determinants of complementary feeding practices among Nepalese children aged 6-23 months: findings from Demographic and Health Survey 2011. BMC Pediatr. 2013, 13, 131. [CrossRef] [PubMed]

58. Morseth, M.S.; Torheim, L.E.; Gebremariam, M.K.; Chandyo, R.K.; Ulak, M.; Shrestha, S.K.; Shrestha, B.; Henjum, S. Tracking of infant and young child feeding practices among 9- to 24-month-old children in Nepal: The MAL-ED Birth Cohort Study. Public Health Nutr. 2017. [CrossRef] [PubMed]

59. Mittal, M.; Bansal, V.; Jain, R.; Dabla, P.K. Perturbing Status of Vitamin B12 in Indian Infants and Their Mothers. Food Nutr. Bull. 2017, 38, 209-215. [CrossRef] [PubMed]

60. Hay, G.; Clausen, T.; Whitelaw, A.; Trygg, K.; Johnston, C.; Henriksen, T.; Refsum, H. Maternal folate and cobalamin status predicts vitamin status in newborns and 6-month-old infants. J. Nutr. 2010, 140, 557-564. [CrossRef] [PubMed]

(C) 2018 by the authors. Licensee MDPI, Basel, Switzerland. This article is an open access article distributed under the terms and conditions of the Creative Commons Attribution (CC BY) license (http://creativecommons.org/licenses/by/4.0/). 